\title{
PRIMARY ECTOPIC PAPILLARY CARCINOMA OF THYROID IN THE LARYNX: AN UNUSUAL PRESENTATION
}

\author{
SHALINI S MENON ${ }^{1}$, BALAKRISHNAN $\mathbf{R}^{1}$, MANNA VALLIATHAN ${ }^{2}$ \\ ${ }^{1}$ Department of ENT-Head and Neck Surgery, Kasturba Medical College, Manipal, Karnataka, India. ${ }^{2}$ Department of Pathology, Kasturba \\ Medical College, Manipal, Karnataka, India. Email: shalini.menon084@gmail.com
}

Received: 05 December 2017, Revised and Accepted: 18 January 2018

\begin{abstract}
Ectopic thyroid is the result of the failure of migration of thyroid along its tract from the floor of the primitive foregut to its final pretracheal position. The incidence of an ectopic lesion in adults is $7 \%$. Most common location is the base of tongue (lingual). Other diverse sites are larynx, trachea, mediastinum, and pericardium. These ectopic tissues may develop the same diseases as the thyroid gland. Here, we report a case of a young female presenting with a foreign body sensation in the throat and on examination revealed a smooth submucosal swelling involving the supraglottis. The entire cyst was excised in toto by KTP 532 laser via an endolaryngeal approach and it was reported as papillary carcinoma of the thyroid. Literature search reported only a few cases of intralaryngeal ectopic thyroid and none with a papillary carcinoma of the larynx. This is the first reported case of papillary carcinoma of thyroid in the larynx.
\end{abstract}

Keywords: Ectopic thyroid, Larynx, Papillary carcinoma.

(C) 2018 The Authors. Published by Innovare Academic Sciences Pvt Ltd. This is an open access article under the CC BY license (http://creativecommons. org/licenses/by/4. 0/) DOI: http://dx.doi.org/10.22159/ajpcr.2018.v11i5.24075

\section{INTRODUCTION}

Ectopic thyroid tissue is a relatively common abnormality due to defective migration of thyroid tissue during embryonic development. The ectopic tissue may be found anywhere along the path of descent of thyroid gland in the anterior midline of the neck. Lingual thyroid is the most common site. The other sites for ectopic thyroid are sublingual, larynx, trachea, mediastinum, and pericardium [1]. Although the malignant transformation of the ectopic thyroid is not frequent, development of papillary carcinoma has been reported. A review of the literature showed only seven cases of the true intralaryngeal ectopic thyroid [2]. A 30-yearold female presented with the left-sided submucosal supraglottic mass. Following radiological evaluation, a microendoscopic-assisted resection was done. It was reported as ectopic thyroid with papillary carcinoma which may pose a diagnostic and therapeutic dilemma for surgeons. To the best of our knowledge, this is the first reported case of ectopic papillary thyroid carcinoma of the larynx.

\section{CASE REPORT}

A 30-year-old female presented with a complaint of a foreign body sensation in the left side of the throat of 3 months duration. The patient had no associated symptoms of dysphagia, change of voice, or breathing difficulty.

A clinical examination by rigid telescopy of the larynx showed a smooth submucosal fullness involving the left aryepiglottic fold, left half of the ventricular band, and adjoining portion of the laryngeal surface of the epiglottis extending on to the left pharyngoepiglottic fold and the adjacent vallecula (Fig. 1). The cords were mobile and the lesion was not obscuring the airway. The examination of neck including the laryngeal framework was normal. The patient underwent laser-assisted excision of the supraglottic mass under general anesthesia. The mass was exposed using a Weerda distensible laryngoscope. Under microendoscopic vision, using KTP 532 laser, the mass was resected in toto (Fig. 2). The gross specimen showed a uniloculated cyst measuring $3.5 \mathrm{~cm} \times 2 \mathrm{~cm}$ $\times 2 \mathrm{~cm}$ with a focally thickened wall (Fig. 3). The histopathological examination showed the cyst to be lined with malignant cells thrown into papillary folds with a fibrovascular core having moderate cytoplasm. The nuclei showed nuclear crowding, anisonucleosis, fine ground glass chromatin, nuclear grooves, and prominent nucleoli. The underlying stroma showed both cellular and hyalinized areas with psammomatous calcification. A diagnosis of papillary carcinoma of the left supraglottis was made (Fig. 4). The subsequent thyroid function test done was normal. A Tc-99m pertechnetate scan done, showed the presence of a normal right lobe of the thyroid with small left lobe and enlarged isthmus. Patchy radiotracer concentration was seen in both the left lobe an isthmus. An ultrasound neck done, showed a hypoechoic nodule measuring $3.5 \mathrm{~mm} \times 2.5 \mathrm{~mm}$ in the thyroid isthmus.

The patient then underwent a total thyroidectomy preserving the parathyroids under general anesthesia. The histopathological examination of the excised gland showed no evidence of malignancy. Post-operative 1-131 scan showed no take up in the region of the larynx (Fig. 5) and a rigid telescopy of the larynx done 3 months later showed no evidence of recurrence.

1-year later, an 1-131 whole body scan was done which showed no evidence of recurrent or metastatic disease. The patient is presently on regular follow-up with thyroxine replacement.

\section{DISCUSSION}

An ectopic thyroid is rare with a reported incidence of one in every $100,000-30,000$ in the general population. The most common location is the base of tongue (lingual ectopia). A review of the literature shows that laryngeal ectopic thyroid is rare. Although more than 175 cases have been reported involving the laryngotracheal region, seven cases involving only the larynx have been reported [2]. Lesions involving the supraglottis may be either a benign laryngeal cyst, an internal laryngocoele, or a primary supraglottic malignancy of larynx. Various theories have been explained by the presence of thyroid tissue in the larynx. It can be a true ectopic intralaryngotracheal thyroid with no connection with the main thyroid gland (Waggoner, 1958), or a false aberrant intralaryngotracheal thyroid connected to the main gland through a defect in the laryngeal or tracheal cartilages (Waggoner, 1958), intraluminal invasion of the larynx or trachea by frank carcinoma can occur. Malignant transformation of the ectopic intralaryngotracheal thyroid is rare [3]. 


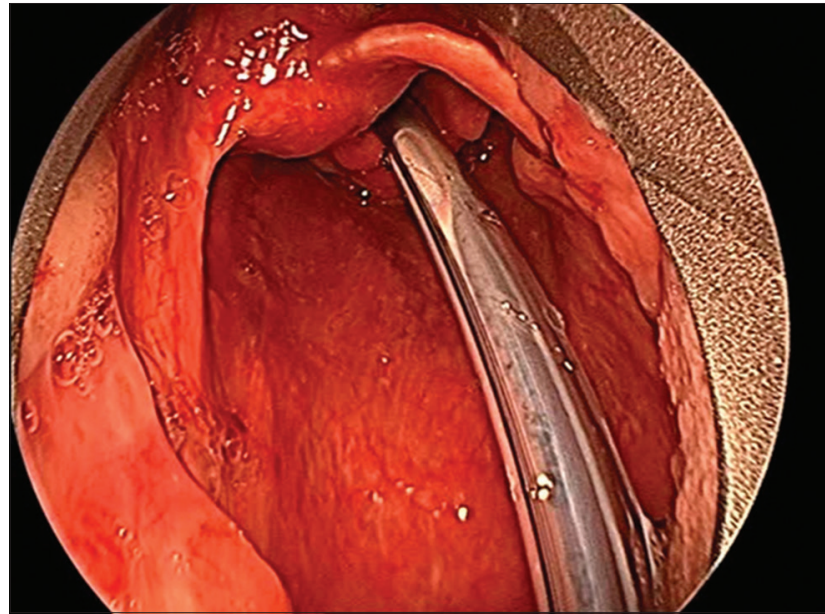

Fig. 1: Smooth cystic lesion involving the left half of the supraglottis

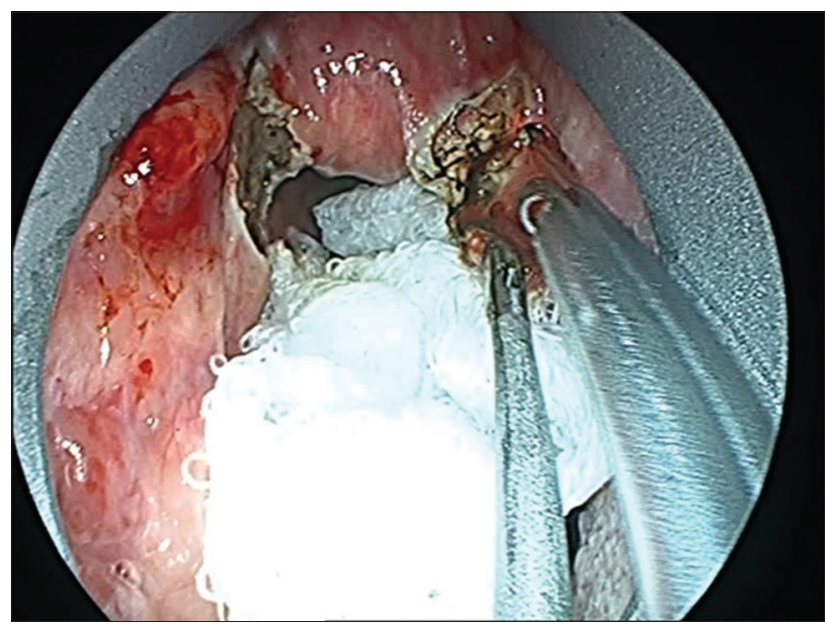

Fig. 2: Microlaryngoscopic KTP laser-assisted excision of the cyst

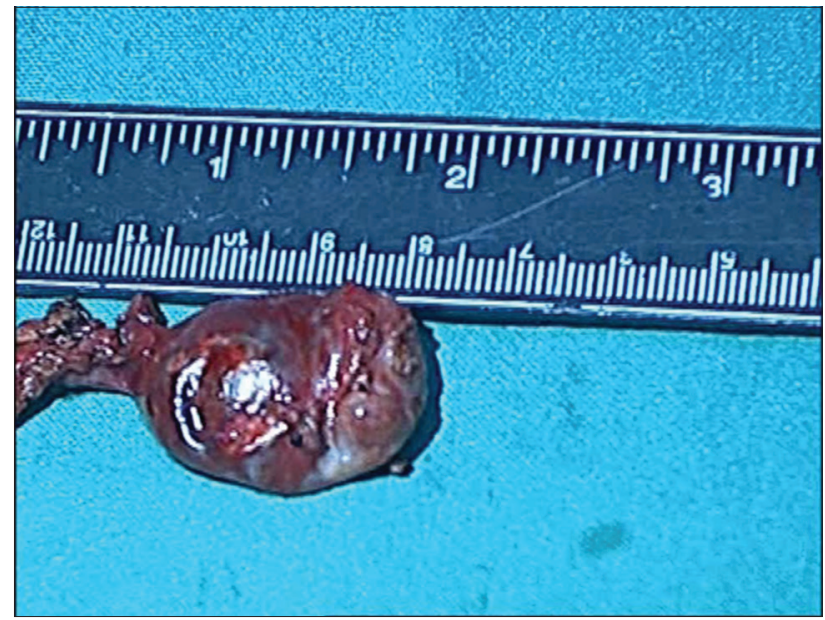

Fig. 3: Entire cyst in toto

A carcinoma arising from an ectopic thyroid tissue is rare. A few cases of papillary carcinoma and follicular carcinoma have been reported in lingual thyroid, thyroglossal cyst, and ectopic thyroid in the mediastinum [4]. To differentiate a carcinoma arising in an ectopic thyroid tissue and a metastatic carcinoma is difficult as in our case. The diagnosis can be made indirectly by taking into account some of the

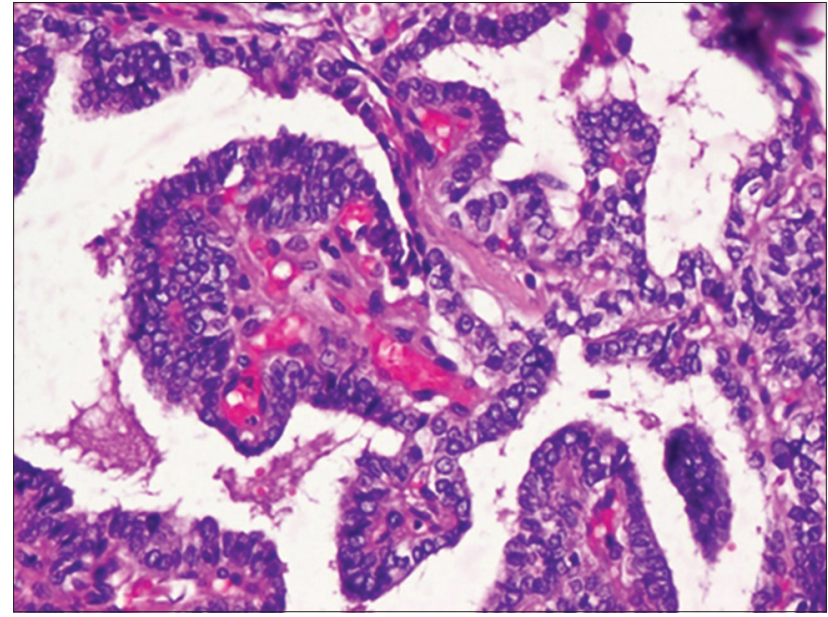

Fig. 4: $\mathrm{H}$ and $\mathrm{E}(\times 150)$ showing features of papillary carcinoma

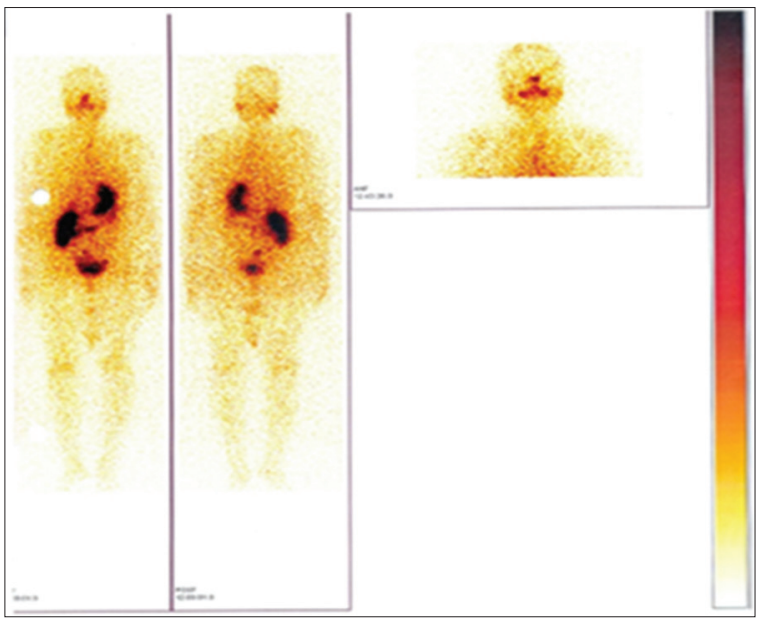

Fig. 5: Whole body 1-131 scan showing no recurrence or metastasis

features such as separate blood supply of the ectopic gland, no personal history of malignancy, and normal or absent orthotopic thyroid with no history of surgery $[2,5]$.

In this case, the patient presented with a submucosal lesion in the region of the aryepiglottic fold of the larynx which was clinically considered to be a benign supraglottic lesion. The computed tomography (CT) scan showed a well-defined lesion involving the supraglottic region, again suggesting a possibility of a benign lesion. In view of the findings, excision biopsy of the supraglottic mass was considered.

To describe an association between the lesion and the normally located thyroid gland, scintigraphy and USG neck was done which showed the presence of normal thyroid gland with no cervical lymphadenopathy which supported the diagnosis of the ectopic thyroid. Scintigraphy is a very important diagnostic tool to detect ectopic thyroid tissue and to show the absence or presence of normal thyroid tissue. In addition to thyroid isotope scanning, a CT scan or magnetic resonance imaging can be done to know the presence of thyroid gland. These imaging studies can also be done to know the extent and location of ectopic tissue for a better presurgical evaluation of the primary, for cervical lymphadenopathy and for intratracheal invasion in case of a malignancy [1].

Among thyroid malignancies, papillary carcinoma has a favorable treatment outcome with a 10-year survival rate of more than $90 \%$ [6]. Due to the presence of malignancy, the patient underwent 
a total thyroidectomy which revealed a normal thyroid gland with no communication with the intralaryngeal tissue and no cervical lymphadenopathy. This gave us further evidence to support the diagnosis of ectopic papillary thyroid carcinoma of the larynx rather than metastasis from the thyroid gland $[6,7]$.

There is no optimal therapeutic strategy described in literature due to the rarity of this clinical entity. Many surgeons state that the surgical treatment of ectopic thyroid tissue in the neck depends on its size and local symptoms $[8,9]$. In an ectopic thyroid tissue, with malignancy, excision of the ectopic tissue followed by total thyroidectomy (if the cervical thyroid is present and normal in position) is advisable. Adequate surgical treatment followed by post-operative radioiodine therapy has offered very good results in papillary carcinoma [10].

\section{CONCLUSION}

Ectopic supraglottic thyroid with papillary carcinoma has not been reported in the literature. Due to its rarity, diagnosis is made postresection on histopathological examination. Surgical resection is the recommended treatment for a laryngeal ectopic thyroid. However, a malignant transformation of this ectopic thyroid tissue warrants further treatment by total thyroidectomy with or without radioiodine ablation.

\section{CONFLICT OF INTEREST}

None.

\section{ACKNOWLEDGMENT}

I would like to thank Dr Kailesh Pujary and Dr D.R Nayak for their constant help.

\section{AUTHOR'S CONTRIBUTION}

Dr. Shalini S Menon has collected the data and drafted the article. Dr. Balakrishnan $\mathrm{R}$ is the primary surgeon and has reviewed the article.
Dr. Manna Valiathan is the concerned pathologist and has also reviewed the article.

\section{REFERENCES}

1. Roh E, Hong ES, Ahn HY, Park SY, Yoon HI, Park KS, et al. A case of mediastinal ectopic thyroid presenting with a paratracheal mass. Korean J Intern Med 2013;28:361-4.

2. Zatoński T, Bolanowski M, Jęrzejuk D, Zatońska K, Kręcicki T. Intralaryngeal ectopic thyroid. Otolaryngol Pol 2014;68:46-9.

3. See AC, Patel SG, Montgomery PQ, Rhys Evans PH, Fisher C. Intralaryngotracheal thyroid - ectopic thyroid or invasive carcinoma? J Laryngol Otol 1998;112:673-6.

4. Hussain D, Waheed S, Haider G, Ibrahim M, Hartung R. Dual ectopy of thyroid tissue: Intratracheal and in nasopharynx, associated with normally located thyroid. J Coll Physicians Surg Pak 2015;25 Suppl 2:S86-8.

5. Mace AD, Taghi A, Khalil S, Sandison A. Ectopic sequestered thyroid tissue: An unusual cause of a mediastinal mass. ISRN Surgery 2011;2011:313626

6. Tian L, Jiao Y, Liu M, Li M, Yao H. Ectopic thyroid papillary carcinoma of nasopharynx associated with adenoid hypertrophy: An unusual presentation. Head Face Med 2014;10:40.

7. Cakmak G, Simsek F, Erturan S, et al. Papillary carcinoma in mediastinal ectopic thyroid tissue accompanying a normal thyroid tissue of the neck: A case report. Turk J Thorac Cardiovasc Surg 2012;20:393-5.

8. Noussios G, Anagnostis P, Goulis DG, Lappas D, Natsis K. Ectopic thyroid tissue: Anatomical, clinical and surgical implications of a rare entity. Eur J Endocrinol 2011;165:375-82.

9. Keles E, Ozkara S, Karlidag T, Ozercan IH. Thyroid tissue connected to normally located thyroid gland: Ectopic or exophytic? Case Rep Otolaryngol 2012;2012:681823.

10. American Thyroid Association (ATA) Guidelines Taskforce on Thyroid Nodules and Differentiated Thyroid Cancer, Cooper DS, Doherty GM, Haugen BR, Kloos RT, Lee SL, et al. Revised American thyroid association management guidelines for patients with thyroid nodules and differentiated thyroid cancer. Thyroid 2009; 19:1167-214. 